\title{
RELATIONSHIP BETWEEN STAGE OF PREGNANCY AND SOME FETAL PARAMETERS IN EARLY PREGNANT MARES
}

\author{
D. REFAAT IBRAHIM MOHAMMAD DERAR
}

Department of Theriogenology, Faculty of Veterinary Medicine, Assiut University.

\section{ABSTRACT}

Received at: $12 / 3 / 2012$

Accepted: 12/4/2012
The aim of the current study was to establish ultrasonic biometric threshold of different uterine contents in thoroughbred mares and characterize the ultrasound changes in the conceptual swelling during the first 75 days of pregnancy. A sequence of ultrasonographic examinations was carried out on 54 pregnant thoroughbred mares at 15, 18, 21, 28, 35, 45, 60 and 75 days of pregnancy during which conceptual swellings and fetal parts were described and measured, respectively. The obtained results revealed that embryo and amniotic vesicle (AV) were detectable by days 21 and 28 days of pregnancy, respectively. Organization (differentiation of the fetus into a morphologically-similar individual) was observed by day 45 , while ossification was obvious by Day 60. Ultrasonographically, the form of the embryonic vesicle changed from round, oblong $(36 / 54,66.67 \%)$ or round $(18 / 54$, $33.33 \%$ ), triangular to irregularly circumscribed on days $15,18,21$ and 28 of pregnancy, respectively. High correlations were found between different studied fetal parameters and gestational age, where the highest correlation was found with diameter of the conceptual swelling (CSD, the conceptus including fluid and membranes, $\mathrm{r}=0.99, \mathrm{P}<0.01$ ), amniotic vesicle diameter (AVD, $\mathrm{r}=0.99, \mathrm{P}<0.01$ ), uterine diameter (UTD, mean diameter of the uterus at the level of the conceptus, $\mathrm{r}=0.99, \mathrm{P}<0.01$ ) and the crown-rump length $(\mathrm{CRL}, \mathrm{r}=0.96, \mathrm{P}<0.01)$ during early pregnancy. In conclusion, the overall data indicated the feasibility and value of ultrasonographic fetometry in thoroughbred mares for evaluation of the early embryonic/fetal development and estimation of gestational age during the first 75 days of pregnancy.

\footnotetext{
العلاقة بين مرحلة الحمل وبعض مقاييس الحميل في الأفراس أثناء الحمل المبكر

ضرار رفعث إبراهيم محمد ضرار

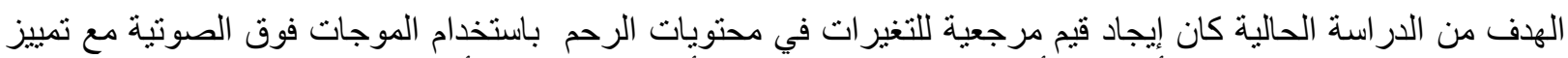

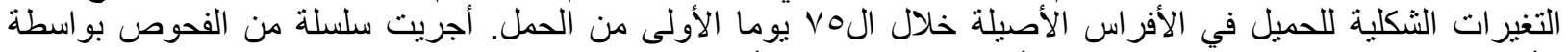

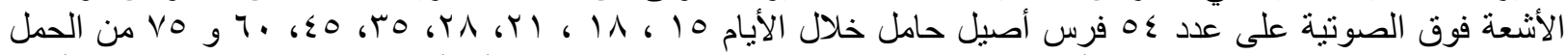

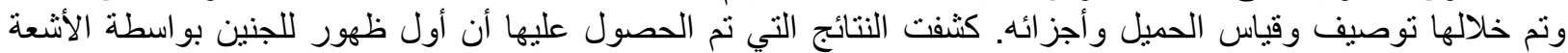
فوق الصوتية كان في اليوم الواحد والعشرين من الحمل بينما أَول ظهور للحوصلة الأمنيونية التي تحيط بالجنين كان في التي
} 
اليوم الثامن و العشرين. لوحظ تمايز الحميل إلى فرد مماتل شكليا للفرد الكامل في اليوم الخامس و الأربعين من الحمل بينما

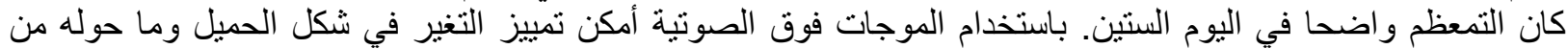

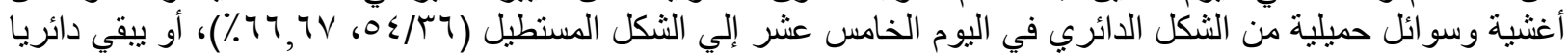

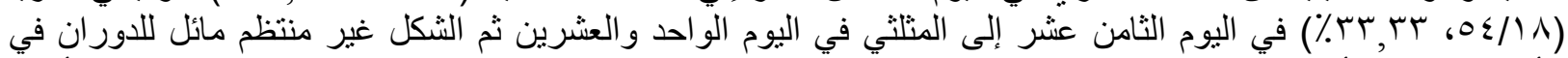

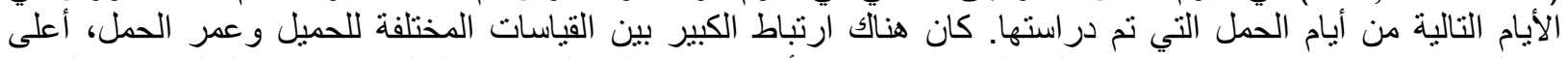

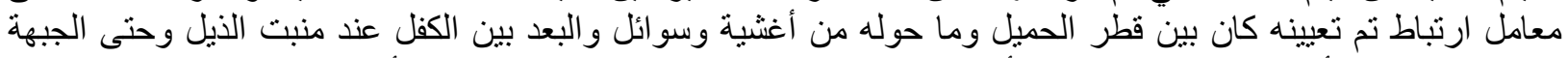

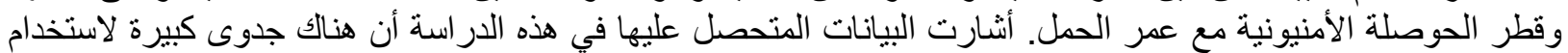

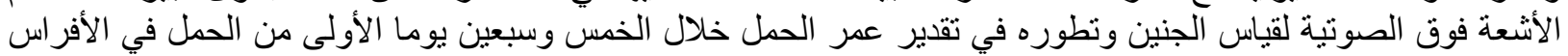

Keywords: Thoroughbred mares, fetal dynamics, early pregnancy, ultrasound.

\section{INTRODUCTION}

There is much interest and concern about the early fetal life of the equine conceptus for many reasons. For one reason, it is a time of highly unique specialization and reproductive strategy. Secondly it is a time of high pregnancy failure and therefore deserves a better understanding (Sharp, 2000). The architecture of the equine conceptus likely plays an important role in its orientation long before proper conceptus-maternal interdigitation occurs. With the advent and subsequent refinement of ultrasonography, characterized by diverse echogenicity (grey scale imaging), it is now possible to obtain more detailed information about different fetal parameters during gestation. Fetal growth can be defined as time-dependent increases in specific geometrical characteristics of the fetus (Deter et al., 1981). When fetal growth is decreased, intrauterine growth retardation present with subsequent increased risk of antepartum fetal death occurred (Ogata et al., 1999). Therefore, the main clinical objectives of antenatal ultrasonography are the identification of fetuses with retarded or excessive growth and the prediction of gestational age. Antenatal ultrasound has been used to measure fetal parameters in many animal species including cattle (Rosiles et al., 2005), donkey (Meira et al., 1998), sheep (Greenwood et al., 2002), goat (Lee et al., 2005) and mare (Curran and Ginther, 1993). Antenatal ultrasonography can provide sequential measurements of same conceptus over different developmental stages. From a practical standpoint, the first examination could be postponed until approximately 18 to 20 days post-ovulation, thus eliminating scanning of mares that are destined to return to estrus. One exception would be scanning of breeds that have a history of twinning or multiple ovulations (e.g. Thoroughbreds). These mares must be examined at day 12 to 15 post-ovulation to most effectively manage manual embryonic reduction. Frequency of subsequent scans will depend on such factors as presence of twins, size and quality of the vesicle and embryo, availability of the mare and economics. Timing of the initial pregnancy examination depends on factors such as breed, economics, convenience and client education. In thoroughbred mares, however, fetal dynamics received little attention from workers in the equine industry and presence of definite criteria to estimate gestational age is lacking. Most previous researchers, in mare reproduction, were interested in studying the process of orientation (Silva and Ginther, 2006), maternal recognition of pregnancy (Allen, 2005), fetomaternal interactions (Ginther, 1998 and Allen, 2001), fetal sex (Curran and Ginther, 1993; Mari et al., 2002) and measuring of the fetal eye (vitreous body) for prediction of parturition date in small ponies (Turner et al., 2006).

Therefore, the aim of the present study was to establish the biometric threshold of different 
fetal parts and organs at which high accuracy level in the estimation of gestational age by ultrasonography is achievable in thoroughbred mares. In addition, the changes in the conceptual swelling during the first 2.5 months of gestation were characterized ultrasonographic in this breed of horse.

\section{MATERIALS and METHODS}

\section{Animals and management}

A group of 54 multiparous non-lactating thoroughbred mares aged from 6 to 10 years and weighing between 550 and $750 \mathrm{~kg}$ was assigned for the present study during the months March-July of the breeding season. Mares in the present study belonged to Shiraoi farm (Shadai corporation, 271 shadai, shiraoicho, shiraoi-gun, Hokkaido 059-0901, Japan) with mean body condition score of 7 (6.5 to 8.0; Henneke et al., 1983) and natural mating not AI- is the only scheduled breeding tool to get these mares in foal. Mares were fed maintenance ration formulated according to NRC standard requirements for open mares with free access to water throughout the period of the study.

\section{Ultrasonographic examinations}

Serial transrectal ultrasonographic examinations were carried out, on daily basis during the estrus period to determine the day of ovulation (when the dominant follicle was no longer present), then on days $15,18,21,28$, $35,45,60$ and 75 days post ovulation. The examinations were performed using real-time, B-mode, diagnostic ultrasound (system XLS; Diagnostic sonar, ALOKA Co. Ltd, Mure, Japan) equipped with $6 / 8 \mathrm{MHz}$ transrectal linear array transducers. To facilitate the access to the fetus at 75 days of pregnancy, a 3.5/5.5 $\mathrm{MHz}$ transrectatal linear array transducer was used. A description for the changes occurring within the conceptual swelling (the uterine contents including the hypoechoic conceptual fluid, conceptual membranes and conceptus) was investigated.

\section{Fetometric parameters}

The earliest moment of detection of the embryo and AV (the amnion containing the conceptus and the amniotic fluid) was recorded. The time of fetal organization into head, body, and limbs was detected. Increased echogenicity in the area of suspected fetal bone formation was considered as the time of ossification. On each ultrasonographic examination, attempts were made to measure the following parameters: A) Uterus and uterine contents including CSD (mean of the vertical and horizontal diameters of embryonic vesicle before the appearance of the amniotic vesicle and later the conceptus including mambranes and fluid), UT (mean thickness of the uterine wall at the antimesometrial attachement), UTD (mean vertical and horizontal diameter of the uterus at the level of the conceptus) and AVD (mean vertical and horizontal diameters of the amniotic vesicle form Days 28 to 75); B) Fetometric parameters including CRL (crown-rump length, a straight line between the fetal crown and the origin of tail), BPD (biparietal diameter, the widest distance between the outer borders of the cranium at an angle of $90 \circ$ to the falx cerebri), CHD (chest depth, a dorso-ventral distance just caudal to the apex of the heart), ABD (abdominal diameter, maximum diameter at the region of the umbilical cord).

\section{Statistical analysis}

Regression and correlation models were fitted to evaluate the relationship between gestational age and each of the studied parameters. The various measurements were considered as being dependent on gestational age. A 5\% significance level was used. The data were analyzed using the General Linear Models procedures of the SPSS-program (2011).

\section{RESULTS}

Out of 54 pregnancies studied, $28(51.85 \%)$ pregnancies found in the right and $26(48.15 \%)$ found in the left uterine horns. The embryonic vesicle was detected in all mares by the $15^{\text {th }}$ day of pregnancy while the embryo was 
obvious by day 21. Changes in the body, and limb buds was firstly observed in ultrasonographic appearance of the embryonic $64.81 \%$ of studied mares $(35 / 54)$ by Day 45 vesicle and conceptual swelling were and in all animals by the $60^{\text {th }}$ day of pregnancy. summarized in Fig. 1. Embryonic vesicle Beginning of the ossification was observed in changed its shape from spherical on Day 15, the head, ribs, and vertebrae in $87.03 \%$ of oblong $(36 / 54,66.67 \%)$ or round $(18 / 54$, mares $(47 / 54)$ by Day 60 of pregnancy. $33.33 \%$ ) on day 18 and changed to a guitarpick or triangular shape by day 21 of pregnancy. From Days 28 to 75 of pregnancy, the shape became irregularly spherical.

Changes in the biometric parameters of the uterus and its contents including the fetal ones were presented in Table 1, Fig. 2 and 3. The stage of pregnancy in the studied mares The embryo and later the fetus changed its correlated signficantly with CSD ( $\mathrm{r}=0.99$, location form the ventral (day 21), dorsal (Day $\mathrm{P}<0.01$ ), AVD $(\mathrm{r}=0.99, \mathrm{P}<0.01)$, UT ( $\mathrm{r}=-0.93$, 28 and 35), lateral (day 45) to finally the $\mathrm{P}<0.05)$, UTD $(\mathrm{r}=0.99, \mathrm{P}<0.05)$, CRL ( $\mathrm{r}=$ ventral aspects of the gravid horn on Day 60 of $0.96, \mathrm{P}<0.01), \mathrm{CHD}(\mathrm{r}=0.90, \mathrm{P}<0.05), \mathrm{ABD}$ gestation. Organization of the fetus into head, $(r=0.92, \mathrm{P}<0.05)$ and $\mathrm{BPD}(\mathrm{r}=0.93, \mathrm{P}<0.05)$.

Table 1: Changes in the biometric parameters of the uterus (mean uterine diameter, UTD and uterine thickness, UT), uterine contents (mean diameter of conceptual swelling, CSD and amniotic vesicle, AVD) and embryo/fetus (mean values for crown rump length, CRL, chest diameter, $\mathrm{CHD}$, abdominal diameter, $\mathrm{ABD}$ and biparietal diameter, $\mathrm{BPD}$ ) during early pregnancy in throughbred mares.

\begin{tabular}{|c|c|c|c|c|c|c|c|c|}
\hline $\begin{array}{c}\text { Stage of } \\
\text { pregnancy }\end{array}$ & CSD & UTD & UT & AVD & CRL & CHD & $\mathrm{ABD}$ & BPD \\
\hline 15 & $1.60 \pm 0.01^{\mathrm{a}}$ & $4.63 \pm 1.08^{\mathrm{a}}$ & $1.88 \pm 0.21^{\mathrm{a}}$ & & & & & \\
\hline 18 & $2.44 \pm 0.05^{\mathrm{a}}$ & $4.64 \pm 0.56^{\mathrm{a}}$ & $1.73 \pm 0.24^{\mathrm{a}}$ & & & & & \\
\hline 21 & $2.55 \pm 0.12^{\mathrm{a}}$ & $4.69 \pm 1.76^{\mathrm{a}}$ & $1.55 \pm 0.07^{\mathrm{a}}$ & & & & & \\
\hline 28 & $3.64 \pm 0.63^{\mathrm{a}}$ & $6.22 \pm 1.46^{\mathrm{b}}$ & $1.43 \pm 0.28^{\mathrm{a}}$ & $2.46 \pm 0.31^{\mathrm{a}}$ & $1.38 \pm 0.04^{\mathrm{a}}$ & $0.33 \pm 0.01^{\mathrm{a}}$ & $0.51 \pm 0.01^{\mathrm{a}}$ & $0.48 \pm 0.01^{\mathrm{a}}$ \\
\hline 35 & $4.58 \pm 1.54^{\mathrm{b}}$ & $8.71 \pm 2.72^{\mathrm{b}}$ & $1.32 \pm 0.13^{\mathrm{a}}$ & $2.56 \pm 0.91^{\mathrm{a}}$ & $2.48 \pm 0.12^{\mathrm{a}}$ & $1.28 \pm 0.04^{\mathrm{a}}$ & $1.38 \pm 0.20^{\mathrm{a}}$ & $0.55 \pm 0.03^{\mathrm{a}}$ \\
\hline 45 & $7.37 \pm 2.01^{\mathrm{c}}$ & $10.02 \pm 1.90^{\mathrm{c}}$ & $1.05 \pm 0.24^{\mathrm{a}}$ & $3.17 \pm 1.39^{\mathrm{a}}$ & $2.60 \pm 0.34^{\mathrm{a}}$ & $1.36 \pm 0.20^{\mathrm{a}}$ & $1.86 \pm 0.11^{\mathrm{a}}$ & $0.58 \pm 0.01^{\mathrm{a}}$ \\
\hline 60 & $9.58 \pm 1.48^{\mathrm{c}}$ & $13.14 \pm 2.59^{d}$ & $0.97 \pm 0.02^{\mathrm{b}}$ & $4.33 \pm 1.76^{b}$ & $6.07 \pm 0.72^{\mathrm{b}}$ & $1.43 \pm 0.12^{\mathrm{a}}$ & $1.98 \pm 0.41^{\mathrm{a}}$ & $1.17 \pm 0.09^{b}$ \\
\hline 75 & $12.56 \pm 2.35^{\mathrm{d}}$ & $18.35 \pm 3.31^{\mathrm{e}}$ & $0.93 \pm 0.01^{b}$ & $5.11 \pm 2.90^{b}$ & $10.67 \pm 2.83^{\mathrm{c}}$ & $3.47 \pm 0.83^{\mathrm{b}}$ & $4.77 \pm 0.65^{b}$ & $2.18 \pm 0.07^{\mathrm{b}}$ \\
\hline $\begin{array}{l}\text { Correlation } \\
\text { coefficient }\end{array}$ & $0.99^{* *}$ & $0.99 * *$ & -0.93 & $0.99 * *$ & $0.96^{* *}$ & $0.90^{*}$ & $0.92 *$ & $0.93 *$ \\
\hline
\end{tabular}

Values with different superscripts are significantly different within the same column $(\mathrm{P}<0.05)$.

*. Correlation is significant at the 0.05 level (2-tailed).

$* *$. Correlation is significant at the 0.01 level (2-tailed). 


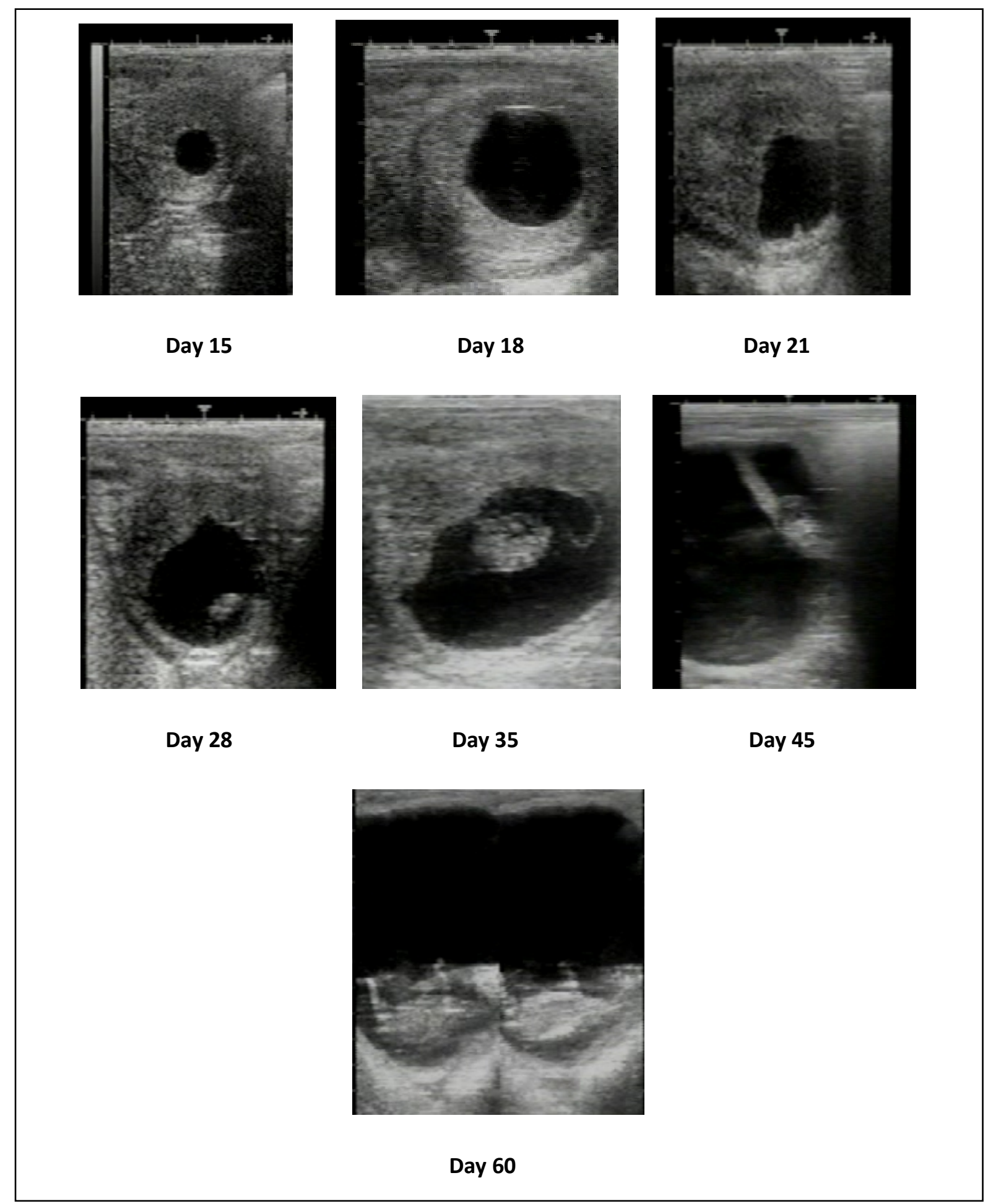

Fig. 1: Changes in the form of the embryonic vesicle and the conceptual swelling from spherical on Day 15, oblong (Day 18), triangular (Day 21) to irrigularly spherical on Day 35, 45, 60 and ultrasonographic appearance of the embryo (before Day 45) and later the fetus (after Day 45) as well as change in its location within the gravid horn from ventral (Day 21), lateral (Day 28), dorsal (Day 35), lateral (Day 45) and eventually ventral (Day 60) in thoroughbred mares $(n=54)$. 

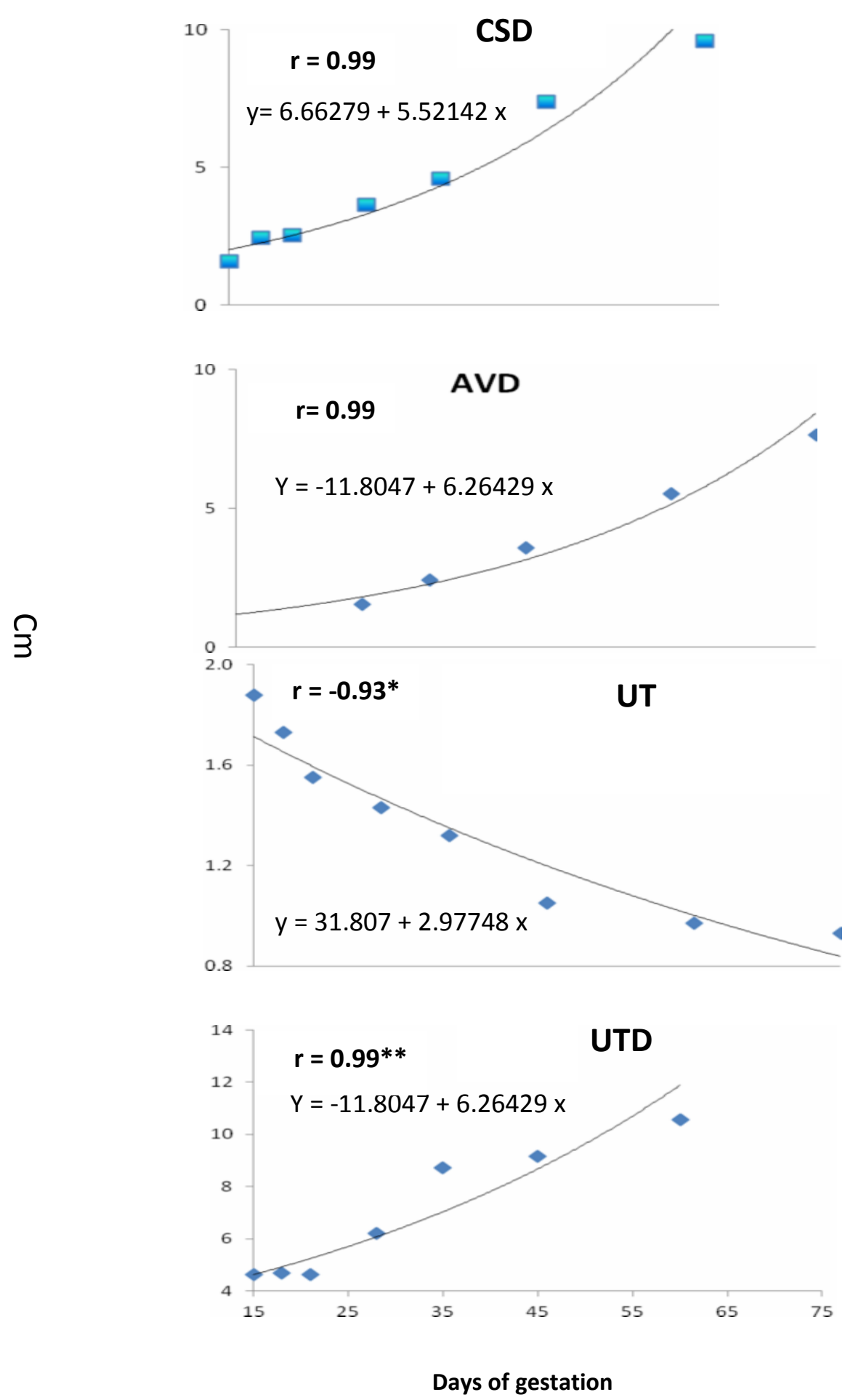

Fig. 2: Correlation between the gestation period in thoroughbred mares $(n=54)$ and the biometry of the conceptual swelling including diameter of the conceptual swelling (CSD) amniotic vesicle (AVD), uterine diameter at the level of the conceptual swelling (UTD) and the uterine thickness at the antimesometrial attachment (UT). ${ }^{*} \mathrm{p}<0.05$ and $* * \mathrm{p}<0.01$. 


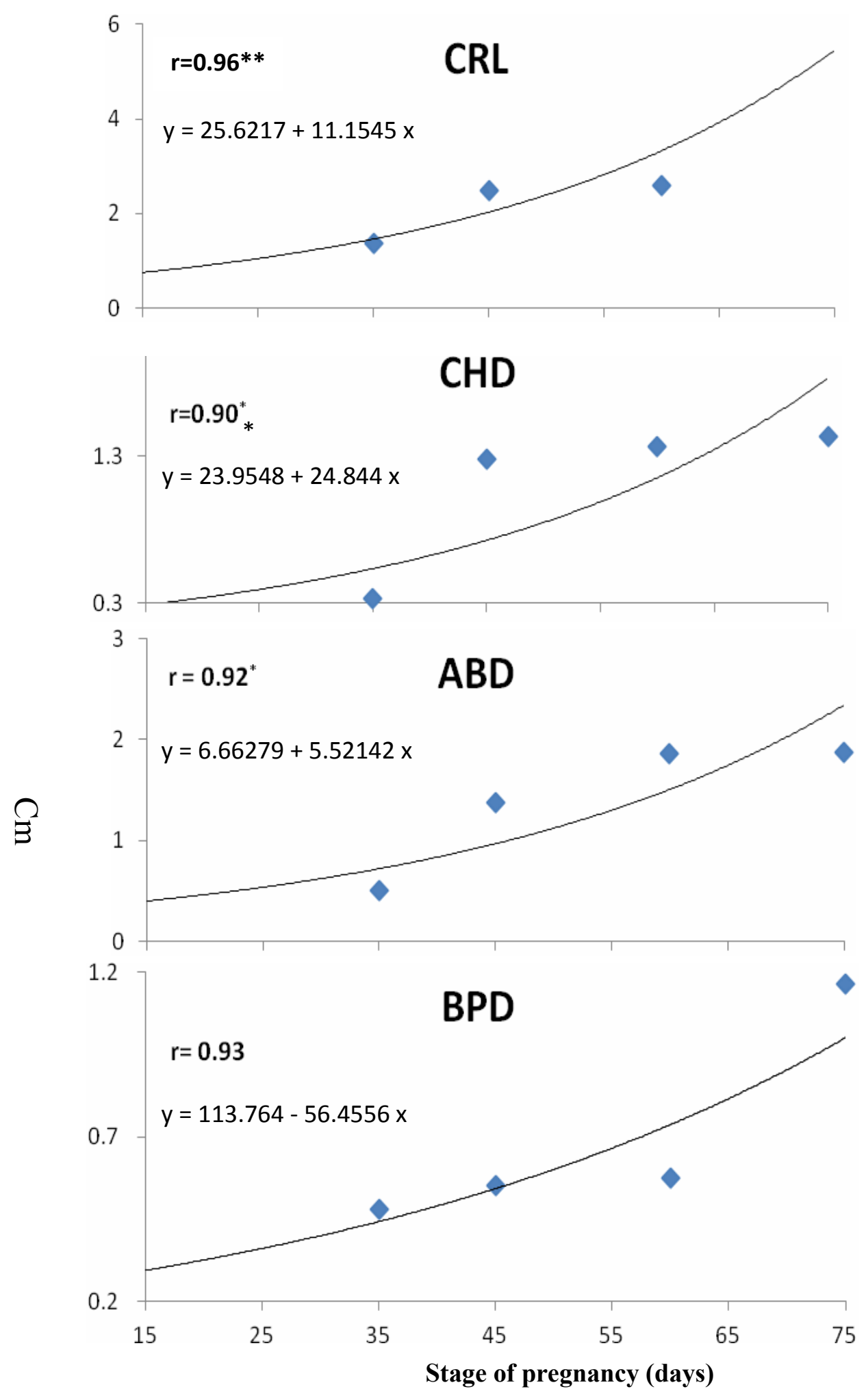

Fig. 3: Correlation (r) between stage of pregnancy in thoroughbred mares and different fetometric parameters like crown rump length (CRL), Chest diameter (CHD), Abdominal diameter (ABD) and Biparietal diameter (BPD) measured ultrasonically $(\mathrm{n}=54) . * \mathrm{p}<0.05$ and $* * \mathrm{p}<0.01$. 


\section{DISCUSSION}

This study used ultrasonography to describe the growth of thoroughbred mare's uterine and conceptual parameters in vivo. It focused on measuring a number of specific body parts and on determining changes in the ultrasonographic characteristics of the conceptus between 15 and 75 days gestation. Currently, the precision of the ultrasonographic measurements was judged by correlation coefficients between growth of these parameters and gestational age, where the highest correlation was found with CSD, UTD, AVD and CRL. The CSD, UTD, AVD and CRL were accessible only during the first trimester of gestation. Our findings are nearly compatible with previous reports (Ginther, 1992; Franciolli et al., 2011). Ginther (1992) reported that crown-rump and head length and width had similar reliability for aging pregnancy up to 100 days. Thereafter, breed and individual variations seemed to reduce the accuracy of head and extremity measurements. Crown rump length had been long used to estimate the gestational age and considered the most reliable parameter for doing that in riding and racing horses (Bergin et al., 1967). The present study confirmed previous results and added CSD and UTD as additional criteria for determining the gestational age in thoroughbred horses in addition to other criteria as AVD, CRL, BPD, CHD and ABD.

The change in the shape of the embryonic vesicle and conceptual swelling from spherical on Day 15 to oblong or remained spherical on day 18 to guitar pick on day 21 in the present study may be attributable to uterine turgidity and thickening of the dorsal uterine wall, especially on each side of the mesometrial attachment (Gastal et al., 1998). Sharp (2000) reported that the equine conceptus remains essentially spherical throughout the first 6 to 8 weeks of pregnancy contradictory to most domestic species in which the chorioallantois expands and elongates tremendously within the first two weeks of pregnancy. The spherical shape is maintained with a progressive increase in diameter over Days 10-16 because the equine embryo is completely enveloped by a tough, elastic glycocalyx known as the equine blastocyst capsule between days 6.5-22 after ovulation (Allen, 2001). In the present study, the embryo and later the fetus changed its location inside the pregnant horn form the ventral (Day 21), dorsal (Day 35), lateral (Day 45) to finally the ventral aspects of the gravid horn on Day 60 of gestation. It has been postulated (Ginther, 1983) that orientation occurs between the time of fixation and the appearance of the irregular shapes. Three factors are believed to interact during orientation: (1) thick (three-layered) and thin (two-layered) portions of the yolk-sac wall; (2) asymmetrical encroachment from thickening of the upper turgid uterine wall on each side of the mesometrial attachment; and (3) the massaging action of uterine contractions (Ginther, 1983 and Ginther, 1985). The interaction of these factors results in the thickest portion of the yolk-sac wall (embryonic pole) rotating to a ventral position (antimesometrial). Differential dorsal thickening of the endometrium that surrounds the embryonic vesicle began during the later days of the mobility phase (Silva and Ginther, 2006). Other workers (Allen, 2005) reported that by Day 21, the embryo, with its primitive beating heart, can be discerned at one pole of the conceptus similar to the present findings. In an anatomical study (Franciolli et al., 2011), organization of embryos into head region, forelimb- buds, and tail spouts occurred between Day 35 and 60, which is approximately similar to the current data. Ossification of the skull, ribs, and vertebrae were indicated in the present study between Days 60 and 75 of pregnancy. Franciolli et al. (2011) reported that ossification centers appeared in the cartilaginous parts of horse's skull at seven week gestation, where the earliest elements to form were spheroid bone on day 35. First indication of ossification in human's embryo was indicated by eight-week gestation (Arey, 1965). In 
accordance with the present study, fetal head nods were first detected at mean Day 40 (Betteridge et al., 1982; Ginther, 1995). The nods can be observed by ultrasound with prolonged and steady observation of a longitudinal section of the fetus. The extent of fetal activity gradually increases to detectable limb movements by mean day 45 . On day 60 the fetus in all the studied mares was found at the ventral aspect of the gravid horn. Similarly, it was reported that the umbilical cord lengthens so that the fetal-amniotic unit reaches the lower wall or ventral aspect of the allantoic sac by day 48 (Ginther, 1983 and 1993). The allantoic sac emerges from the embryo proper a few days later. The allantois lifts the embryo proper from the floor of the conceptus and assumes a larger and larger proportion of conceptus volume at the expense of the yolk sac (Ginther, 1998).

In conclusion, this study provided important information about fetal development in thoroughbred mares, at which a diagnosis of gestational stages during the first 75 days of pregnancy corresponding to the changes in the shape of the conceptual swelling and dynamic changes in uterine contents can be made with high accuracy.

\section{REFERENCES}

Allen, W.R. (2001): Fetomaternal interactions and influences during equine pregnancy. Reproduction, 121: 513-527

Allen, W.R. (2005): Maternal recognition and maintenance of pregnancy in the mare Anim Reprod, 2(4): 209-223.

Arey, L.B. (1965): Developmental Anatomy. W.B. Saunders company, Philadelphia and London. 90-117.

Bergin, W.C.; Gier, H.T.; Frey, R.A. and Marion, G.B. (1967): Developmental horizons and measurements useful for age determination of equine embryos and fetuses. Proc. Ann. Conv. Amer. Assoc. Equine Pract., New Orleans. pp. 179.

Betteridge, K.J.; Eaglesome, M.D.; Mitchell, D.; Flood, P.F. and Beriault, R. (1982):
Development of horse embryos up to twenty-two days after ovulation: observations on fresh specimens. J. Anat, 135: 191-209.

Curran, S. and Ginther, O.J. (1993): Ultrasonic fetal gender diagnosis during Months 5 to 11 in mares. Theriogenology, 40(6): 1127-1135

Deter, R.H.; Harrist, R.B.; Hadlock, F.P. and Carpenter, R.T. (1981): The use of ultrasound in the assessment of normal fetal growth: a review. J. Clin. Ultrasound, 9: 481-495.

Franciolli, A.L.R.; Cordeiro, B.M.; $d a$ Fonseca, E.T.; Rodrigues, M.N.; Sarmento, C.A.P.; Ambrosio, C.E.; de Carvalho, A.F.; Miglino, M.A. and Silva, L.A. (2011): Characteristics of the equine embryo and fetus from days 15 to 107 of pregnancy. Theriogenology, 76: 819-832.

Gastal, M.O.; Gastal, E.L.; Torres, C.A.A. and Ginther, O.J. (1998): Effect of oxytocin, prostaglandin F2a, and clenbuterol on uterine dynamics in mares. Theriogenology, 50: 521-534.

Ginther, O.J. (1983): Fixation and orientation of the early equine conceptus. Theriogenology, 19: 613-623.

Ginther, O.J. (1985): Dynamic physical interactions between equine embryo and uterus. Equine Vet J Suppl, 3: 41-47.

Ginther, O.J. (1992): Reproductive biology of the mare: Basic and applied aspects. 2.ed. Cross Plains, WI, USA: Equiservices Publishing. pp. 391-393.

Ginther, O.J. (1993): Equine fetal kinetics: Allantoic-fluid shifts and uterine-horn closures. Theriogenology, 40: 241-256.

Ginther, O.J. (1995): Ultrasonic imaging and animal reproduction. Book 2. Horses. Cross Plains, WI: Equiservices Publishing.

Ginther, O.J. (1998): Equine Pregnancy: Physical interactions between the uterus and conceptus. AAEP Proceedings, 44: 73-104.

Greenwood, P.L.; Slepetis, R.M.; McPhee, M.J. and Bell, A.W. (2002): Prediction 
of stage of pregnancy in prolific sheep using ultrasound measurement of fetal bones. Reprod Fertil Dev., 14: 7-13.

Henneke, D.R.; Potter, G.D.; Krieder, J.L. and Yeates, B.F. (1983): Relationship between body condition score, physical measurements and body fat percentage in mares. Equine Vet. J., 15: 371-372.

Lee, Y.; Lee, O.; Cho, J.; Shin, H.; Choi, Y.; Shim, Y.; Choi, Y.; Shim, Y.; Choi, W.; Shin, H.; Lee, D.; Lee, G. and Shin, S. (2005): Ultrasonic measurement of fetal parameters for estimation of gestational age in Korean black goats. J. Vet. Med. Sci., 67: 4 97-502.

Mari, G.; Castagnetti, C. and Belluzzi, S. (2002): Equine fetal sex determination using a single ultrasonic examination under farm conditions. Theriogenology, 58(6):1237-43.

Meira, C.; Ferreira, JC.; Papa, F.O. and Henry, M. (1998): Ultrasonographic evaluation of the conceptus from days 10 to 60 of pregnancy in Jennies. Theriogenology, 49: 1475-1482.

Ogata, Y.; Nakao, T.; Takahashi, K.; Abe, H.; Misawa, T.; Urushiyama, Y. and Sakai,
J. (1999): Intrauterine growth retardation as a cause of perinatal mortality in Japanese black beef calves. Zentrabl Veterinarmed A, 46: 327-334.

Rosiles, V.A.; Galina, C.S.; Maquivar, M.; Molina, R. and Estrada, S. (2005): Ultrasonographic screening of embryo develop- ment in cattle (Bos indicus) between days 20 and 40 of pregnancy. Anim Reprod Sci, 90: 31-37.

Sharp, D.C. (2000): The early fetal life of the equine conceptus. Anim Reprod Sci, 61: 679-689.

Silva, L.A. and Ginther, O.J. (2006): An Early Endometrial Vascular Indicator of Completed Orientation of the Embryo and the Role of Dorsal Endometrial Encroachment in Mares. Biol Reprod, 74: 337-343.

SPSS. (2011): SPSS 20.0 user's guide: $\mathrm{http}: / /$ spss.en.softonic.com/.

Turner, R.M.; McDonnell, S.M.; Feit, E.M.; Grogan, E.H. and Foglia, R. (2006): Real-time ultrasound measure of the fetal eye (vitreous body) for prediction of parturition date in small ponies. Theriogenology, 66: 331-337. 